\title{
Fostering Employability through Versatility within Specialisation in Medical Translation Education ${ }^{1}$
}

\begin{abstract}
The current increase of automation (Rodríguez 2017; Massey/Wieder 2018) and the emergence of new needs and forms of communication are triggering substantial changes in the translation profession, in the role of the translator and in translator education. Previous studies (Muñoz-Miquel 2014, 2016a, 2018) have shown the rich variety of tasks beyond those traditionally considered - that medical translators perform in the workplace, including heterofunctional translation, editing, or community management. The ability to develop new skills and to adapt continuously to the changing needs of the market is one of the essential characteristics of the translator in the $21^{\text {st }}$ century. That is why we consider it of critical importance that, together with specialisation, versatility is promoted in translator education. In this article, we explore the notion of versatility and propose a teaching strategy that incorporates it and can contribute to improving the employability of future translators. Specifically, we put forward some pedagogical proposals for the English-Spanish language combination that promote diversification of competences and tasks within a narrow specialisation - the medical and healthcare field — in order to provide (future) translators with the versatility necessary to respond to new demands and thus be more employable. Our approach is based on the results of surveys of professional medical translators on the tasks and roles they perform, as well as on our own teaching experience in a master's degree programme in medical translation.
\end{abstract}

\section{Keywords}

medical translation; postgraduate training; versatility; employability; socio-professional study; professional tasks

\section{Introduction}

The present time of technological change, increasing automation (Rodríguez 2017), growth of neural machine translation (Massey/Wieder 2018) and emergence of new communication needs is triggering substantial changes in the translation and interpreting profession, and even calling into question the very existence of translation as a human activity, as well as translation education as we currently think of it.

At the same time, there is a growing interest in fostering the employability of graduates (Calvo et al. 2010; Peverati 2013; Álvarez-Álvarez/Arnáiz-Uzquiza 2017; Rodríguez 2017) and in conducting empirical studies to provide data on the tasks currently required of professional translators. Professional and academic specialisation in a particular type of translation (and more specifically in a particular task or a single genre or subject area) has traditionally been considered

1 This article was written within the framework of the following research projects: "Creation of multilingual resources for improving doctor-patient communication in Public Health Services" (HIPOCRATES) (PGC2018-098726-BI00), supported by the Spanish Ministry of Economy and Competitiveness; "Creation of resources for teaching communicative skills in medical and healthcare fields" (AICO/2019/182), supported by the Valencia Regional Government; and "Development of online multilingual resources for improving the Informed consent as a multimodal communication act" (UJI-B2018-67), supported by Universitat Jaume I

\footnotetext{
* Ana Muñoz-Miquel

Gentt Group

Departament de Traducció-

i Comunicació

Universitat Jaume I

Email: munoza@uji.es
}

$\begin{array}{ll}\text { Vicent Montalt } & \text { Isabel García-Izquierdo } \\ \text { Gentt Group } & \text { Gentt Group } \\ \text { Departament de Traducció- } & \text { Departament de Traducció- } \\ \text { i Comunicació } & \text { i Comunicació } \\ \text { Universitat Jaume I } & \text { Universitat Jaume I } \\ \text { Email: montalt@uji.es } & \text { Email: igarcia@uji.es }\end{array}$


an effective way to foster employability (Henter 2016). However, some studies (Muñoz-Miquel 2014, 2016a, 2018) have shown that specialised translators carry out a wide variety of tasks, and this could be indicative that specialisation is not in conflict with versatility but rather the opposite. Both can coexist.

Therefore, our concern in this paper is not so much in employability itself but in the role that versatility - the ability to change one's perspective to adapt to new professional situations and develop existing and new competences in response to changing market needs (Montalt 2011) should play in the curriculum of the specialised translator, as a possible tool that can contribute to make him/her more employable. This proposition is framed within the broader argument that in an era of growing automation, new professional paths in which the human factor is not only desirable but inevitable and of critical importance can — and should — be explored. And this may involve redefining - or even extending - the tasks, roles and responsibilities (Angelone 2018; Massey/Wieder 2018) expected of translators, which could influence the directions that translator training should take.

In the European Higher Education Area (EHEA) a clear distinction is made between the bachelor's degree - clearly focused on the development of a general education - and the master's degree, more oriented towards specialisation and, therefore, with a greater projection towards the labour market. In this context, then, the concept of employability is presented as closely linked to master's training. Therefore, in this article we will address the training of future medical translators at master's degree level. We have chosen this speciality and this education level for three reasons. The first is that medical translation is a strategic and thriving niche of the international market place for professional translators (Montalt/González 2007), which is being influenced by recent technological developments and changes in communication needs. Secondly, specialisation is a critical issue in postgraduate training and has to respond to specific market requirements in a highly internationalised context (Montalt 2002; Calvo 2011; Kelly 2010; Toudic, 2012). Thirdly, we have carried out empirical research with translators (Muñoz-Miquel 2014, 2016a, 2018) which has provided us with information about professional practice in this sector.

With the overall goal of providing pedagogical insights that may be useful to medical translation trainers, this paper will (1) analyse the results from a survey of practising medical translators about the professional tasks they perform and consider how these results can inform training, and (2) provide some examples of teaching tasks as well as some guidance of good teaching practice in medical translation education based on the survey's results and on our own experience as teachers of the Master's degree in Medical and Healthcare Translation at the Universitat Jaume I.

The paper is structured as follows: Section 2 discusses the notions of specialisation and employability in translation; Section 3 describes the methods used in the exploratory case study and the main results obtained; Section 4 offers some examples of tasks that could be included in the design of a versatile curriculum; and Section 5 presents some concluding remarks.

\section{Specialisation and employability in translation}

From the translation industry perspective, it is emphasised that specialising (in the sense of "narrowing down" the object of the translator's work) is necessary to be able to respond to current market demands with the level of quality required. This is reflected in statements by authors such as Martin (2011: online): "No translator can be expected to have the knowledge required to translate all types of documents well and within a reasonable amount of time", or Henter (2016: 59): "Translators need to specialize in a concrete area to be able to effectively work in the profession", to quote a couple of examples.

However, within the field of Translation Studies, the concept of specialisation is contentious in the sense that there is no general agreement on its definition, as it is clear from the many studies that have addressed the issue in one way or another (Hurtado 2001; Gouadec 2007; Mayoral/ 
Díaz 2011; Montalt 2012; Shreve 2012; etc.). In this regard, Pym (2011: 12; our translation) argues the following:

\begin{abstract}
I fear we are missing a great opportunity [the EHEA reform] to reorganise master's degrees precisely by translation specialisations. [...] It would be more socially useful (at least in terms of graduate employability) [...] to have highly specialised MAs (a model programme could be the Master's Degree in Medical and Healthcare Translation at the Universitat Jaume I in Castellón). We could have one master's programme for training in audiovisual translation techniques, another for legal translation, and so on. Of course, to organise training in this way we would have to decide what we mean by specialisation $[\ldots]$.
\end{abstract}

One of the works that have adopted the most comprehensive approach to the problem of specialisation in translation is that of Mayoral/Díaz (2011). In these authors' view, there is a mixture of typologies, sometimes arising from a confusion between textual specialisation and professional specialisation. As they $(2011: 26)$ put it:

In translation, the adjective specialised has traditionally been used in different and overlapping senses, including 'related to each of the different sub-classes within translation' (horizontal axis of range $^{2}$ ) and 'requiring special skill' (vertical axis of intensity, a parameter that needs to be examined in the light of professional experience).

In general terms the criteria that have most commonly been used to deal with specialisation, especially when referring to training, are language combinations and directionality, mode of translation (e.g., interpreting, audiovisual translation, written translation, etc.), degree of textual specialisation (general versus specialised translation) and subject area (e.g., scientific, medical, economic, legal, etc.) (Hurtado 2001; Mayoral/Díaz 2011; Montalt 2012; García-Izquierdo 2016a). Authors such as Shreve (2012), for their part, advocate specialisation in particular tasks, arguing, from a cognitivist perspective, that expertise is task-specific, and that although knowledge and content are important elements of expertise, higher levels of performance are developed in specialised sub-domains of the translation task.

As we can see, there is no clearly established frame of reference. However, the most consistent and operational criterion has proved to be subject area (Mayoral/Díaz 2011: 60). The specific case we are concerned with, that of medical translation, has been recognised by both the academic community and the professional world as a speciality defined by its subject matter. Although it has traditionally been associated with highly specialised texts, medical translation encompasses a wide spectrum of participants, communicative situations and text genres (Montalt/González 2007; Muñoz-Miquel 2016b; García-Izquierdo 2016b), and this, as we shall see in Section 4, has important repercussions for training.

As previously seen, some authors link specialisation with employability, a critical notion that is part of the new Skills Agenda for Europe (European Ministers Responsible for Higher Education 2015) established by the European Union and is one of the central elements of the Europe 2020 Strategy. Employability is defined as "the ability to gain initial meaningful employment, or to become self-employed, to maintain employment and to be able to move around the labour market" (Working Group on Employability 2009: 5). However, the definition of this concept is not entirely clear: "the term [employability] itself is also still understood differently by the various stakeholders and it is very frequently interchangeable with that of 'employment' which is governed and affected by the different world contexts" (Rodríguez 2017: 108). In our opinion, the concepts of 'employability' and 'employment' should not be confused. In this regard, "even if common goals towards achieving employability have been defined, the reality of how these goals are applied in practice is very different across countries" (Rodríguez 2017: 108). This is why our analysis is limited to the context of the English-Spanish translation. What seems evident is that "con-

2 Horizontal axis of range (textual types according to the theme of the text: legal, scientific...; according to the text genre or function) and vertical axis of intensity (degree of specialization: general translation or specialized translation) (Mayoral/Díaz 2011: 26). 
stant changes in the labour market call for the ability to develop new competences and skills" (Rodríguez 2017: 108). Therefore, in the curricular design it is necessary to envisage these changes.

Authors such as Vandepitte (2009), Calvo et al. (2010), Thelen (2016) or Galán-Mañas (2017, 2018), among others, argue that the competences needed for employability can be summed up in two key concepts: entrepreneurial competence and interpersonal competence. However, an increasing number of scholars (Pym 2005; Kelly 2007; Morón 2016; Morón/Medina 2016; Calvo 2017; Rodríguez 2017; etc.) also highlight the need to focus on cross-disciplinary competences and to identify new professional profiles so as to make Translation Studies more flexible. The idea is to foster the students' ability to develop the new skills they may need in a constantly changing labour market (Montalt 2011; European Ministers Responsible for Higher Education 2015). The acquisition and development of new skills is what we will refer to in the following pages as versatility in education.

Turning to employability, Morón (2012) criticises the excessive rigidity of the translator's profiles that were used as the basis for designing the current bachelor's degrees in Translation and Interpreting in Spain and considers that this rigidity can affect employability, since no room for versatility is left. On the other hand, studies carried out on graduates entering the employment market are scarce - at least in the Spanish context - (Calvo 2006; Morón 2009; Álvarez-Álvarez/Arnáiz-Uzquiza 2017; Galán-Mañas 2017), have certain limitations (in terms of statistical representativeness or lack of consideration of hybrid profiles, among others), and focus only on a bachelor's degree level. More empirical studies that take into account employability at master's degree level and consider a wider variety of professional profiles are therefore needed. ${ }^{3}$

To enhance employability, cooperation between universities (trainers and scholars), professionals (and their associations) and the translation industry (employers) is also needed (Thelen 2016) and "formal academic training should not be subordinated, but rather complemented, by employers' input" (Rodríguez 2017: 112).

In this article, drawing on professional translators' perceptions and opinions, we will focus on the contribution we can make from an educational institution such as a university, and will propose some new skills relevant to medical translators' training, leaving aside the rates of employment of Spanish postgraduates. To this end, the following section will present some of the results of an exploratory case study based on surveys administered to professional translators which, together with our experience as teachers of a master's degree programme in medical translation, will allow us to offer our approach to improve the curricular design at the master's level in this speciality in Spain. In this way, we will try to provide the necessary skills in education to achieve versatility and, with it, future employability.

\section{Case study conducted}

This case study consisted on surveying practising medical translators through an online questionnaire. The aim of this questionnaire was to collect information on the medical translators' professional profile (employment status and tasks performed) and their opinion about the trade-off between versatility and specialisation. In the following section, we will describe the main aspects of the methods used.

3 In the European context we have the example of the OPTIMALE project (Optimising Professional Translator Training in a Multilingual Europe) at master's degree level (Toudic 2012), which links specialisation (at master's level) and employability, and fosters cooperation between employers, universities and teachers, establishing the current and future competences demanded by employers (by means of surveys) and exchanging teaching experiences between master's degree programmes. 


\subsection{Methods and design}

The target population of the study was medical translators working in the English-Spanish language combination and engaged in medical translation, whether exclusively or in combination with other translation activities or specialities.

The questionnaire was designed in Google Forms and consisted of 10 questions, of which one was used to ensure that the population met the language combination criterion. These questions covered a variety of topics: employment status (including the companies in which those who are in-house translators work in), percentage of the respondents' work that entails translation-related tasks in the medical and healthcare fields, professional tasks performed, and opinion on versatility and specialisation. We also collected information on some basic demographic data, i.e. gender, age and type of graduate-level education received. All the questions were closed, with the exception of one, which was open-ended and intended to complement a precedent question of tasks carried out.

We distributed the questionnaire among translators who are members of Tremédica (International Association of Translators and Writers of Medical and Related Sciences), the association that can be regarded as most representative of the community, since it is the only specific organisation of its kind currently in existence. The questionnaire was completed by $39^{4}$ informants, which represents a response rate of $35 \%$ (the total number of member translators at the time in which the questionnaire was sent out was 112). The data were compiled and analysed in May 2018.

To design the questionnaire and, more specifically, the question on tasks performed, which is the one of greatest interest to this study, we mainly based on the following sources of information:

- The results on a larger empirical study (see Muñoz-Miquel 2014, 2016a, 2018) on the academic and professional profile of medical translators (tasks they perform, genres and subjects they translate, clients they work for, documentary resources they use, difficulties they encounter, etc.) and the competences they consider necessary in medical translation.

- Our own experience as teachers of a master's degree in medical translation as well as the professional experiences and paths that former students of the master's degree describe and discuss in an annual professional and academic encounter which is organised as part of the activities offered by the master's degree. ${ }^{5}$

The aforementioned empirical study, which included responses from 167 informants collected in 2013, yielded some interesting results (see references above) regarding the tasks that translators carry out as part of their professional work. These results showed that, in addition to translation itself, many translators also carried out other activities, such as reviewing or proofreading $(76 \%)$, terminology and document management (29\%), directing processes for selecting translators $(20 \%)$, project management $(18 \%)$, adapting specialised texts for patients and the general public (17\%), and writing original medical texts (7\%). In an open question about what other tasks they performed, the respondents referred not only to activities that respond to technological changes (post-editing), but also to those that go beyond what is traditionally considered a translation-related task (Mossop 2016). Some examples were:

- $\quad$ Adapting documents on medical products for the Spanish market.

- Turning specialised medical genres into others also aimed at specialists (such as research articles into summaries, posters or conference papers).

- Managing and creating content on social media (Facebook, Twitter, etc.) related to biomedical communication (e.g., transmission on such media of what is happening at a medical conference).

4 We collected 41 questionnaires, but two had to be discarded because they did not meet the language-combination requirement.

5 The reader will find more information on these encounters at http://www.tradmed.uji.es. 
- Adapting texts to a "neutral" variety of Spanish.

- $\quad$ Performing activities related to popularisation of medicine and science (producing articles and monographs for general readers, moderating scientific book clubs, etc.).

- Consultancy in multinational companies.

- $\quad$ Providing assistance to foreigners in situations of dependency.

- $\quad$ Running a hospital translation and interpreting department.

- Acting as an executive secretary for medical conferences.

In the following section, we will present the results of the case study, which grounds on the tasks identified in the 2013 study.

\subsection{Results}

\subsubsection{Socio-demographic data}

The sample was composed of $80 \%$ women and $20 \%$ men. The mean age was 44 years; the youngest respondent was 25 years old and the oldest, 60 . Regarding the type of graduate-level education the respondents had received, 64\% had studied Translation and Interpreting (or related) or Philology (or related), and 31\% had studied Medicine (or related) or Biology (or related). The remaining 5\% had studied another degree related to science that was not included in the provided options (that is, Engineering and Physics).

\subsubsection{Employment situation}

The translators were mostly self-employed (87\%), which is the commonest employment status in the translation profession (Pym et al. 2012: 3). Only 13\% worked in-house. Of the nine in-house translators, three worked in pharmaceutical companies, two at hospitals or health centres, two in translation agencies and two in international companies not related to the translation industry. Regarding the percentage of work activity that entails translation-related tasks in the medical and healthcare fields, 38.5\% worked exclusively, or almost exclusively (at least $75 \%$ of working hours) in this field, versus $61.5 \%$ who combined it with other types of translation or professional activities.

\subsubsection{Professional tasks performed}

As already mentioned in Section 3.1, in this question we included as options those tasks that were commonest according to our previous empirical study. We also included other tasks that we expected to be performed by the translators on the basis of the most recent studies carried out on professional integration (e.g., Álvarez-Álvarez/Arnáiz-Uzquiza, 2017). To formulate the question we used a Likert scale of five values in which informants had to indicate how frequently (5: Very frequently; 4: Frequently; 3: Occasionally; 2: Rarely; 1: Never) they performed the tasks indicated.

Table 1 provides descriptive statistics of the data set: mean, standard deviation (SD), minimum and maximum values, and skewness, which is a coefficient that measures the asymmetry of a distribution. A negative coefficient indicates that the data lean to the right (the values are closer to 4 or 5), and a positive value shows that the data lean to the left (the values are closer to 1 or 2 ). Table 1 also includes the percentage of translators that had ever performed the given tasks, irrespective of the frequency. 


\begin{tabular}{|c|c|c|c|c|}
\hline Tasks performed & Mean (SD) & [Min; Max] & Skewness & $\begin{array}{c}\text { Percentage of } \\
\text { translators }\end{array}$ \\
\hline Translation. & $4.7(0.7)$ & {$[2 ; 5]$} & -2.2 & $100 \%$ \\
\hline Revising translations. & $3.7(1.1)$ & {$[1 ; 5]$} & -0.5 & $97 \%$ \\
\hline Copy-editing (ortotypography, style). & $3.0(1.4)$ & {$[1 ; 5]$} & -0.2 & $74 \%$ \\
\hline Terminology and document management. & $2.1(1.2)$ & {$[1 ; 5]$} & 0.9 & $62 \%$ \\
\hline Reviewing content. & $2.4(1.4)$ & {$[1 ; 5]$} & 0.4 & $59 \%$ \\
\hline Localisation. & $1.8(1.0)$ & {$[1 ; 4]$} & 0.9 & $46 \%$ \\
\hline Post-editing. & $2.0(1.3)$ & {$[1 ; 5]$} & 1.1 & $44 \%$ \\
\hline Teaching (languages/translation). & $1.7(1.0)$ & {$[1 ; 5]$} & 1.3 & $41 \%$ \\
\hline $\begin{array}{l}\text { Adapting specialised texts for patients and the general } \\
\text { public. }\end{array}$ & $1.7(1.1)$ & {$[1 ; 5]$} & 1.6 & $38 \%$ \\
\hline $\begin{array}{l}\text { Adapting texts to the Spanish spoken in different } \\
\text { countries or to a more "neutral" variety of Spanish. }\end{array}$ & $1.9(1.3)$ & {$[1 ; 5]$} & 1.2 & $38 \%$ \\
\hline Selecting/recruiting translators/collaborators. & $1.6(1.0)$ & {$[1 ; 4]$} & 1.4 & $33 \%$ \\
\hline $\begin{array}{l}\text { Cultural adaptation of texts on products for the } \\
\text { Spanish market. }\end{array}$ & $1.7(1.1)$ & {$[1 ; 5]$} & 1.4 & $33 \%$ \\
\hline Project management. & $1.5(1.0)$ & {$[1 ; 5]$} & 1.9 & $28 \%$ \\
\hline Writing original texts. & $1.5(1.1)$ & {$[1 ; 5]$} & 2.2 & $28 \%$ \\
\hline Editing texts. & $1.5(0.9)$ & {$[1 ; 4]$} & 1.8 & $28 \%$ \\
\hline Subtitling/dubbing. & $1.3(0.8)$ & {$[1 ; 5]$} & 3.2 & $23 \%$ \\
\hline Mediating/interpreting in hospitals. & $1.5(1.0)$ & {$[1 ; 5]$} & 2.1 & $21 \%$ \\
\hline $\begin{array}{l}\text { Adapting medical material to a different format for the } \\
\text { same receiver. }\end{array}$ & $1.3(0.7)$ & {$[1 ; 4]$} & 2.4 & $21 \%$ \\
\hline Creating content for websites. & $1.3(0.8)$ & {$[1 ; 5]$} & 3.5 & $18 \%$ \\
\hline Desktop publishing (DTP). & $1.3(0.6)$ & {$[1 ; 4]$} & 2.8 & $18 \%$ \\
\hline Conference interpreting. & $1.2(0.5)$ & {$[1 ; 3]$} & 2.5 & $15 \%$ \\
\hline Managing/creating content on social media. & $1.1(0.4)$ & {$[1 ; 3]$} & 4.7 & $5 \%$ \\
\hline
\end{tabular}

Table 1. Descriptive statistics of the data set.

The first finding that stands out is that no task was marked with a 'Never' value (see mean and percentage of translators), which shows that all of them are currently required in the professional market to a greater or lesser extent. This also indicates that in this professional environment there is a variety in the tasks performed by translators, who, despite being more devoted to translating or copy-editing, are also called upon to carry out many other different tasks.

We can see that the tasks traditionally associated with the role of the translator, such as equifunctional translation between different languages (100\%), revision (in the sense of comparing originals and translations; 97\%), copy-editing (74\%) and terminology and document management (creating glossaries, style guides, etc.; 62\%), are the most frequent. However, a remarkable percentage of translators has at some point performed tasks related to what has been called "user-centered translation" (Suojanen et al. 2015), that is, adaptations, intralingual translations (Zethsen 2009) and heterofunctional translations (Nord 2009) of all kinds: adapting specialised texts for patients (38\%); adapting texts to different varieties of Spanish or to a more neutral one (38\%); adapting, from a cultural point of view, texts on products for the Spanish market (33\%); adapting medical material to different formats for the same receiver (21\%). Although further studies with larger populations are needed, these figures could indicate that in the professional market the translator can also be seen as an "adapter" or communication facilitator in a broader sense.

Regarding the tasks that are more directly linked to the growing development of neural machine translation such as post-editing, Table 1 shows that, although the skewness is positive, a considerable amount of translators ( $44 \%$ ) post-edit, of whom $24 \%$ post-edit very frequently. As suggested earlier, even though more representative studies are required, we could hypothesise that new 
technologies are factors that are playing a part in changing the work of translators (EMT Board 2017; Rodríguez 2017; Massey/Wieder 2018).

Among the 11 responses recorded to the open question on what other tasks they performed in the medical and healthcare field, these were predominantly related to linguistic validation processes, such as cognitive interviews and assessment of translatability. Other tasks mentioned were the following:

\footnotetext{
- Harmonising documents and translations (such as summaries of product characteristics or patient information leaflets).

- $\quad$ Organising medical conferences.

- $\quad$ Carrying out interviews with doctors on new products.

- Assisting in the production of short videos on medical topics.
}

\subsubsection{Opinions on versatility and hyperspecialisation}

As seen in Section 2, both in the field of Translation Studies and in the professional market, attitudes towards (the desirability or otherwise of) specialisation, particularly with regard to fostering employability, vary widely. We therefore wanted to find out whether, for the purposes of enhancing employability in the field of medical and healthcare translation, the informants considered it preferable 1) to be versatile (in other words, to be capable of changing one's perspective to adapt to new professional situations and of developing skills in response to new tasks and needs), or 2) to be hyperspecialised (that is, to specialise strongly in a specific subject, type of text or task), or whether they thought that 3 ) both views were equally valid.

On this point, a large majority ( $80 \%$ ) felt that both views were equally valid and the remaining $20 \%$ came down in favour of versatility as a means of enhancing employability. It is striking that none of the informants saw hyperspecialisation as the only way to increase one's chances of entering the employment market. These opinions are therefore consistent with our initial premise, since we consider that one can hyperspecialise in a particular subject area (in this case medical translation) and still be versatile.

\section{Our 'Inverted-funnel' educational approach}

In this section we present our teaching strategy, which, as already mentioned, is based on the above results, our previous empirical studies, and our experience in designing the general framework of the Master's degree in Medical and Healthcare Translation and in training medical translators for more than 15 years. Our objective is not so much to design specific teaching tasks but rather to establish a general framework that can serve as a basis for curriculum design from the standpoint of versatility within specialisation. In this "inverted funnel" approach, the focus of attention is initially narrowed, restricting itself to a particular subject area, and then expands like a wide-angle lens to embrace a varied range of possible tasks and roles within that area.

In our teaching strategy we seek to achieve diversity within the framework of a gradation of difficulty that facilitates the teaching-learning process, as well as establishing more or less direct links between the various types of tasks.

Transcription of medical content can be a good way to initiate the process of familiarising oneself with the concepts and terminology specific to the subject area. This task may seem tedious in itself, but if it is combined with terminology development or editing and revision it takes on greater significance.

Updating translations is a task of intermediate difficulty which can be linked in a fairly natural way to transcription and revision/copy-editing activities. Another task of a linguistic nature that 
could be incorporated into a training programme in medical translation is neutralisation of Spanish for an international market.

Regarding standardisation and internationalisation we include assessing the translatability of originals and harmonising documents and translations, particularly of summaries of product characteristics and patient information leaflets for medicinal products.

As already noted in the previous section, post-editing is an activity that is clearly in the ascendant due to the rapid growth of machine translation. One of the tasks that can prove most useful and productive in developing a critical approach in this area is to compare the results of a machine translation (Google Translate, DeepL, PAHOMTS, etc.) with those of a human translation in a range of genres. Comparative activities of this kind can be accompanied by a process of debate and reflection in the classroom on the time and effort expended in each case. In relation to quality control, our teaching strategy could accommodate some back-translation activity.

With regard to compiling terminology resources, we propose a cross-curricular approach whereby the resources produced have practical applications in other training activities within the same course or in other courses. An extremely valuable activity in this respect is creating glossaries that include determinologised equivalents so as to be able to produce various adapted versions from the same specialised source text using a range of determinologisation procedures.

As the surveys have confirmed, editing and revising translations are very common tasks in the professional sphere. They are directly related to quality, which, as is well known, is a relative concept in the profession; in other words, it depends on the specific nature of each assignment and on the needs and preferences of each client. Our teaching strategy includes working with different degrees of quality according to the job, ranging from a translation for very limited internal purposes that is not for publication to one that will be published and must conform to a particular house style. Analysing and reflecting on the style guides of various publishers, media outlets and organisations can be a way of acquiring an awareness of the relative and specific nature of quality.

At a possibly higher level on the scale of complexity, one could introduce a type of task that involves revising and editing a heterofunctional translation and providing a reasoned explanation of that revision and editing process according to parameters of equivalence different from those used in equifunctional translation. In addition, the genre variant can be introduced in revision and editing tasks and combined with that of the nature of the assignment.

From the point of view of complexity and difficulty, an intermediate point between revision and editing tasks in equifunctional and in heterofunctional translations would be revising and copy-editing originals, where the problem of equivalence disappears and other important issues emerge as higher priorities, such as the structure of the text, the clarity with which specialised concepts are expressed and the style. For teaching purposes a link can also be made with revising and copy-editing originals as a preliminary step towards producing original texts, a much more complex task.

In the light of the surveys it is important to pay attention to new genres that have recently emerged. PRO (patient-reported outcomes), for example, is an increasingly prominent medical genre in professional translation practice. It is basically an instrument for measuring the outcomes of a particular drug or procedure according to the perceptions of groups of patients. Adapting to those groups of patients who come from a particular language and culture performs a crucial function when translating texts belonging to this genre. Linguistic validation is the instrument used to assess understanding of the questions in the questionnaire. In our teaching strategy PRO can be used to address issues related to the cultural determinants that affect the relevance and comprehensibility of the target text.

Tasks that involve adapting texts for specific groups of readers offer great teaching potential, since they require a series of strategic operations, some of which, at the most professional level, entail a high degree of complexity. It is essential, for example, to know the specific preferences and expectations of both the target readership and the organisation in which the communication 
takes place (hospital, patients' association, national or international organisation, pharmaceutical company, media outlet, etc.). It is also important to decide which information in the source text is important and which can be dispensed with, and even what information should be introduced in the target text to make it really relevant to those it is addressed to. In a training context such as the current one in which the teaching strategy focuses largely on equifunctional translation, this type of task requires support and facilitation both in theoretical terms (doctor-patient communication, patient empowerment, genre shift, asymmetries between source genre and target genre, heterofunctional translation, the problem of equivalence, the notion of quality, etc.) and at the practical and methodological level (using and exploiting parallel texts, comprehensibility as a translation criterion, ad hoc terminological solutions, etc.). In the medical and healthcare sphere this adaptation can go in two main directions: patients and the general public. There are many factors that can determine the adaptation criteria, ranging from age and ethnicity to the disease or phase of the disease the patient is undergoing. There are also many text genres that can come into play, from informed consents to prevention campaigns.

However, adaptation should not always be seen as a process of simplification or popularisation enabling experts to communicate with non-experts. As is clear from the results of our case study, there is another type of adaptation which consists of turning specialised medical genres into other genres also aimed at specialists, such as turning research articles into summaries, posters or conference papers. In these cases, a possible idea for a teaching application might involve focusing, for example, on the differences between specialised genres. Specifically, some kind of learning task could be formulated to explore the differences between a research article and a conference paper with exactly the same scientific information. This type of task enables one to address the question of multimodality in conference presentations, where the oral mode is combined with the written and the audiovisual.

Another possible teaching application is learning to advise scientists participating in national or international conferences on rhetorical issues related to pronunciation, diction, rhythm, staging, the linguistic quality of the presentation and even its structure, coherence and cohesion.

From a curriculum design point of view, one of the advantages for teaching purposes of introducing translation adapted for specific target groups is that it acts as a bridge towards writing original texts from information given. In this area the notion of equivalence almost entirely disappears and the whole strategy is based on the target reader, who may have various profiles, from patients and the general public to healthcare professionals or researchers. We might, for example, consider creating original texts and content for websites or newsletters for official associations of healthcare professionals, research groups that want to publicise their contributions and to enable them to reach the general public in the form of news stories, interviews, etc., or patients' associations that would like to make their presence felt on the web.

This teaching strategy can be extended in a natural way to tasks that involve managing and creating content on social media (Facebook, Twitter, etc.) related to biomedical communication. Translation students are fully immersed in digital culture and are seasoned users of social media. It is a matter of taking advantage of this expertise and applying it to the field of professional communication. A possible type of task consists of exposing students to the type of discourse commonly used in transmissions on those media of what is happening at a medical conference. The next step is to produce texts emulating the discourse that professionals in particular fields tend to use; for example, an international cardiology conference transmitted via Twitter.

In a more peripheral sphere but concentrating again on text production, our teaching strategy includes the possibility of creating and maintaining blogs on medical translation, dealing with topics such as analysis of resources and tools, translation problems and other issues related to the profession. Lastly, focusing on communication management rather than text production, we propose organising conferences (particularly those aspects that have to do with communicating and disseminating information), interviewing doctors about new products and assisting in the production of short videos on medical subjects. 
The types of tasks exemplified above can be linked to the Competence Framework of the European Master's in Translation (EMT), in which competence is defined as "the proven ability to use knowledge, skills and personal, social and/or methodological abilities, in work or study situations and in professional and personal development" (EMT Board 2017: 3). The EMT Competence Framework seems to be a relevant conceptual tool in our approach because it is applicable to master's level and it takes employability very much into account, since:

[it] aims to consolidate and enhance the employability of graduates of Master's degrees in translation
throughout Europe. [...] It also takes into account the research outcomes on translation and translator
competence reported by the translation studies research community and the changes that have affected
the language services industry since then (EMT Board 2017: 3).

In our view, our 'inverted-funnel' approach to medical translation education can be used to acquire and develop many of the skills in the EMT Competence Framework in the five different areas: language and culture, translation, technology, personal and interpersonal, and service provision.

It should be borne in mind that this framework "sets out a common set of learning outcomes for EMT Master's degree programmes" (EMT Board 2017: 4), so "[i]ndividual programmes may, of course, deliver a much wider range of competences, skills and knowledge in areas that are not included in this Framework" (EMT Board 2017: 4). For this reason, in our approach we take into account the acquisition and development of competences that are specific and relevant in the field of medical and health translation and interpreting (i.e. the acquisition of thematic and terminological knowledge, the ability to carry out advanced searches, the acquisition of cultural knowledge, etc.), as authors such as Montalt/González (2007) or Muñoz-Miquel (2016b) point out.

Finally, within the teaching framework we have presented we would like to emphasise the importance of: working in collaboration, achieving real work assignments as a team; online socialisation; being exposed to communication problems typical of medical and healthcare contexts; making the most of synergies and interdisciplinary dialogue between students of different academic backgrounds (translation, medicine, nursing, language and literature, veterinary science, etc.); and putting greater emphasis on the potentialities and particularities of each student.

\section{Final remarks}

In this article, we have presented some pedagogical proposals to foster employability through versatility. Although the socio-professional data on which we partially base are limited and cannot be taken as representative of current professional reality, they can help us to generate new research questions and refine hypothesis, and to re-think and re-orient the training of future professionals in an attempt to anticipate potential market niches in terms of professional tasks.

Translators currently face two great challenges: increasing automation and new human communication needs. Both of these determine the new roles and tasks of professional translators and should serve to raise awareness of a process of change and reconceptualisation of translation activities that must have consequences in the educational sphere. In this new scenario, specialisation in a subject area and the ability to adapt to new communication and information management needs within that subject area, in this case the medical and healthcare field, are equally important.

The data we have on the tasks performed by professional translators enable us to establish a teaching strategy we have called the "inverted funnel" approach: greater specialisation in a subject area goes hand in hand with more possibility of thoroughly exploring a varied range of tasks which go beyond equifunctional translation of texts aimed at experts on the subject. We believe that this strategy, combining subject specialisation ("content-based translator training" [Montalt 2012]) and versatility, could trigger an increase in the employability of graduates with medical translation degrees. This teaching strategy consists, essentially, of incorporating into the teachinglearning process a series of tasks and roles which traditionally have either been relegated to a minor presence and level of importance or have gone entirely unnoticed. The data from the empirical 
study, despite not being representative, throw light on the real nature of medical translation, embracing a broad continuum of genres (some of which have emerged very recently, such as PRO), reader profiles, contexts of use and types of tasks.

In addition to the questionnaire administered to professional medical translators, some of the research projects carried out by the GENTT group in recent years ${ }^{6}$ have enabled us to detect new potential market niches. These research projects focused on improving clinical communication in multilingual and multicultural settings and showed that 1) professional translators are in an advantageous position to undertake the processes of writing and translating, both inter- and intralingually, texts aimed at certain groups of patients, and of improving their comprehensibility, 2) the training of medical professionals in communication skills with patients from different cultures could benefit from the contributions of experts in medical and healthcare translation and interpreting. These new avenues, which are also evident in the GENTT research projects that are currently in progress, ${ }^{7}$ go beyond translation and interpreting as professions to which training has traditionally been directed and place us in a new interdisciplinary and interprofessional perspective which we should continue to explore through research.

\section{References}

Álvarez-Álvarez, Susana/Arnáiz-Uzquiza, Verónica 2017: Translation and interpreting graduates under construction: do Spanish translation and interpreting studies curricula answer the challenges of employability? In The Interpreter and Translator Trainer 11(2-3), 139-59.

Angelone, Erik 2018: Translator Training for New Intercultural Consulting Roles within the Language Industry. Paper presented at the $4^{\text {th }}$ International Conference on Research into Didactics of Translation (didTRAD). Barcelona: Universitat Autònoma de Barcelona.

Calvo Encinas, Elisa 2006: Orientación profesional para futuros licenciados de Traducción e Interpretación: estrategias centradas en las necesidades del estudiantado. In Bravo Utrera, Sonia/García López, Rosario (coords.), Estudios de traducción: problemas y perspectivas. Las Palmas de Gran Canaria: Universidad de Las Palmas de Gran Canaria, 633-649.

Calvo Encinas, Elisa 2011: Translation and/or Translator Skills as Organising Principles for Curriculum Development Practice. In Journal of Specialised Translation 16, 5-25.

Calvo Encinas, Elisa 2017: Servicios de valor añadido en contextos situacionales en Traducción: de los proyectos al portafolio. In Revista Digital de Investigación en Docencia Universitaria, 11(2), 136-154.

Calvo Encinas, Elisa/Kelly, Dorothy/Morón, Marián 2010: A project to boost and improve employability chances among Translation and Interpreting graduates in Spain. In Pellatt, Valerie et al. (eds.), Teaching and Testing Interpreting and Translating. (Intercultural Studies and Foreign Language Learning). Vol. 2. Berlin: Peter Lang, 209-226.

EMT Board 2017: European Master's in Translation. Competence Framework 2017. https://ec.europa.eu/info/sites/ info/files/emt_competence_fwk_2017_en_web.pdf

European Ministers Responsible for Higher Education 2015: Yerevan Communiqué. http://www.mab.hu/web/doc/kulfold/Yerevan_Communique.pdf.

Galán-Mañas, Anabel 2017: Programa para la mejora de la empleabilidad de los egresados en Traducción e Interpretación. Un estudio de caso. In Conexão Letras, 12(17), 153-171.

Galán-Mañas, Anabel 2018: Aprender a emprender en el grado de Traducción e Interpretación. In: Barceló, M. Tanagua/Velasco, Carmen (eds.), Evaluación, direccionalidad y orientación profesional en los estudios de Traducción e Interpretación. Málaga: EDA Libros, 33-55.

García-Izquierdo, Isabel 2016a: Organising Specialized (medical) Knowledge in Academic and Professional settings. Patient Information Genres. In Garzone, Giuliana/Heaney, Dermot/Riboni, Giorgia (eds.), Language for Specific

6 "Improving interlingual and intercultural clinical communication: new methods for training health professionals" (FFI2015-67427-P), supported by the Spanish Ministry of Economy and Competitiveness, and "Development of online multilingual resources for the improvement of Informed Consent as an act of multimodal communication" (UJIB2018-67), supported by Universitat Jaume I.

7 "Creation of multilingual resources for improving doctor-patient communication in Public Health Services" (HIPOCRATES) (PGC2018-098726-B-I00), supported by the Spanish Ministry of Economy and Competitiveness; "Creation of resources for teaching communicative skills in medical and healthcare fields" (AICO/2019/182), supported by the Valencia Regional Government; and "Development of online multilingual resources for improving the Informed consent as a multimodal communication act" (UJI-B2018-67), supported by Universitat Jaume I. 
Purposes. Research and Translation across Cultures and Media. Cambridge: Cambridge Scholars Publishing, 148168.

García-Izquierdo, Isabel 2016b: At the cognitive and situational interface: Translation in healthcare settings. In Translation Spaces 5(1), 20-38. (Reedited in 2018 in Ehrensberger-Dow, Maureen/Englund-Dimitrtova, Birgitta (eds.): Exploring the Situational Interface of Translation and Cognition, 19-37.).

Gouadec, Daniel 2007: Translation as a Profession. Amsterdam/Philadelphia: John Benjamins.

Henter, Sarah 2016: How Happy are Translators with their Studies? In Current Trends in Translation Teaching and Learning E 3, 24-66.

Hurtado Albir, Amparo 2001: Traducción y Traductología: introducción a la Traductología. Madrid: Cátedra.

Kelly, Dorothy 2007: Translator competence contextualized. Translator training in the framework of higher education reform: In search of alignment in curricular design. In Kenny, Dorothy/Ryou, Kyongjoo (eds.), Across Boundaries. International Perspectives on Translation Studies. Newcastle: Cambridge Scholars, 128-142.

Kelly, Dorothy 2010: Translation Didactics. In Gambier, Yves/van Doorslaer, Luc (eds.), Handbook of Translation Studies, Volume 1. Amsterdam/Philadelphia: John Benjamins, 389-396.

Martin, Charles 2011: Specialization in Translation - Myths and Realities. Translation Journal, 16 (2) [online]. http:// translationjournal.net/journal/56specialist.htm (accessed 1 December 2019).

Massey, Gary/Wieder, Regine 2018: Educating translators for new roles and responsibilities: Interfacing with corporate and technical communication. Paper presented at the $4^{\text {th }}$ International Conference on Research into Didactics of Translation (didTRAD). Barcelona: Universitat Autònoma de Barcelona.

Mayoral Asensio, Roberto/Díaz Fouces, Óscar 2011: La traducción especializada y las especialidades de traducción. Castelló de la Plana: Universitat Jaume I.

Montalt Resurrecció, Vicent 2002: Entre el aula y la profesión: reflexiones y propuestas en torno a la formación de traductores especializados. In Alcina Caudet, Amparo/Gamero Pérez, Silvia (eds.), La traducción cientifico-técnica y la terminología en la sociedad de la información. Castelló de la Plana: Universitat Jaume I, 219-230.

Montalt Resurrecció, Vicent 2011: Hacia una visión perspectivista de la traducción. In Panace@, 12(33), 1-3.

Montalt Resurrecció, Vicent 2012: A case for content-based translator tranining. Paper presented at the $1^{\text {st }}$ International Conference on Research into the Didactics of Translation (didTRAD). Barcelona: Universitat Autònoma de Barcelona.

Montalt Resurrecció, Vicent/González Davies, Maria 2007: Medical Translation Step by Step: Learning by Drafting. Manchester/Kinderhook: St. Jerome.

Morón, Marián 2009: Percepciones sobre el impacto de la movilidad en la formación de traductores. La experiencia del programa LAE (Lenguas Aplicadas Europea). Unpublished PhD dissertation. Granada: Universidad de Granada.

Morón, Marián 2012: La figura del traductor-intérprete en procesos de internacionalización: el caso de las convocatorias de becas del ICEX. In Sendebar 23: 251-274.

Morón, Marián 2017: Del "texto" al "contexto" en la traducción comercial: bases de un modelo para la transversalidad de la traducción. In Sendebar 28, 95-112.

Morón, Marián/Medina, Ana 2016: La competencia del traductor que no "traduce": el traductor en ámbitos de internacionalización empresarial. In MonTI 8, 225-255.

Mossop, Brian 2016: "Intralingual translation": A desirable concept? In Across Languages and Cultures 17(1), 1-24.

Muñoz-Miquel, Ana 2014: El perfil del traductor médico: análisis y descripción de competencias especificas para su formación. PhD dissertation. Castelló de la Plana: Universitat Jaume I.

Muñoz-Miquel, Ana 2016a: Bridging the gap between professional practice and university training through socioprofessional research: The case of medical translation. In Martín de León, Celia/González-Ruiz, Víctor (eds.), From the lab to the classroom and back again: Perspectives on translation and interpreting training. Frankfurt am Main: Peter Lang, 257-294.

Muñoz-Miquel, Ana 2016b: La traducción médica como especialidad académica: algunos rasgos definitorios. In Hermēneus. Revista de Traducción e Interpretación 18, 235-267.

Muñoz-Miquel, Ana 2018: Differences between linguists and subject-matter experts in the medical translation practice: An empirical descriptive study with professional translators. In Target 30:1,24-52.

Nord, Christiane 2009: El funcionalismo en la enseñanza de traducción. Mutatis Mutandis 2:2, 209-243.

Peverati, Costanza 2013: Translation In Modern Language Degree Courses. A Focus On Transferable Generic Skills. In inTRAlinea 15 [online]. http://www.intralinea.org/archive/article/1932 (accessed 1 December 2019).

Pym, Anthony 2005: Training Translators: Ten Recurrent Naiveties. In Translation Today 2, 3-6. 
Pym, Anthony 2011: Preface to the work by Mayoral Asensio, Roberto/Díaz Fouces, Óscar 2011: La traducción especializada y las especialidades de traducción. Castelló de la Plana: Universitat Jaume I.

Pym, Anthony/Grin, François/Sfreddo, Claudio/Chan, Andy L. J. 2012: The Status of the Translation Profession in the European Union (DGT/2011/TST). Final Report. Luxembourg: European Commission [online]. http://ec.europa.eu/ dgs/translation/publications/studies/translation_profession_en.pdf (accessed 1 June 2019).

Rodríguez de Céspedes, Begoña 2017: Addressing employability and enterprise responsibilities in the translation curriculum. In The Interpreter and Translator Trainer 11(2-3), 107-122.

Shreve, George. M. 2012: Learning From The Best: What Expertise Studies Tells Us About Translation Didactics. Keynote speech presented at the $1^{\text {st }}$ International Conference on Research into the Didactics of Translation (didTRAD), Barcelona: Universitat Autònoma de Barcelona.

Suojanen, Tytti/Koskinen, Kaisa/Tuominen, Tina 2015: User-centered translation. London \& New York: Routledge.

Thelen, Marcel 2016: The practice-oriented translator training curriculum: An example. Current Trends in Translation Teaching and Learning E 3, 163-200.

Toudic, Daniel (ed.) 2012: The Optimale employer survey and consultation, WP4 synthesis report. Brussels: European Comission [online]. http://www.translator-training.eu/attachments/article/52/WP4_Synthesis_report.pdf (accessed 1 June 2019).

Vandepitte, Sonia 2009: Entrepreneurial Competences in Translation Training. In Proceedings of the conference The Changing Face of Translation. Portsmouth: University of Portsmouth.

Working Group on Employability 2009: Report to Ministers, Bologna Conference, Leuven/Louvain-la Neuve 28-29 April 2009 [online]. http://www.ond.vlaanderen.be/hogeronderwijs/bologna/conference/documents/2009_employability_WG_report.pdf (accessed 1 June 2019).

Zethsen, Karen K. 2009: Intralingual translation: an attempt at description. In Meta 54 (4), 795-812. 